\title{
Democracia y Estado de partidos. (Re)leer a García Pelayo ${ }^{1}$
}

\section{Invitación a la lectura}

El iuspublicista español Manuel García Pelayo, después de vivir plenamente el siglo XX, falleció en Caracas, Venezuela en 1991, país que lo recibió durante un largo exilio, después de un periplo que se inicia en Argentina y sigue en Puerto Rico, exilio que se inicia a principios de la década del 50 , ya que éste no aceptó el exilio interior que le deparaba estar en el derrotado bando Repúblicano en que sirvió como oficial del Ejército y haber pertenecido a la categoría de prisionero de guerra. García Pelayo se formó sólida y eruditamente en Viena y Berlín, profesando tempranamente la docencia universitaria en España antes de la Guerra Civil, llegando a conocer de primera fuente a los grandes iuspublicistas de época y los grandes debates de la era de Weimar, y conocer también la crisis de las noveles repúblicas de la primera postguerra y el ascenso de los fascismos europeos, y la segunda gran guerra y sus consecuencias.

Después de los difíciles "tiempos de silencio" de la década del 40 en España de que nos habla Martín Santos y en pleno exilio exterior, García Pelayo aceptó la invitación a afincarse en Venezuela, donde fundó y dirigió el Instituto de Estudios Políticos y desarrolla un brillante magisterio para iberoamericanos desde la Universidad Central de Caracas. Con la transición a la democracia en España, Garcia Pelayo regresa definitivamente en 1979 a su país y es nombrado magistrado y presidente del Tribunal Constitucional, lugar donde cumple un rol clave en los primeros años de la democracia española. El alejamiento de García Pelayo del Tribunal Constitucional, estuvo marcado por sinsabores e incomprensiones, unido a un delicado estado de salud, que lo acompañarán

Profesor de Dereho Constitucional, Iniversidad de Chile Universidad Diego sortales. en su regreso a Venezuela en 1987, abandonando sus últimos quehaceres docentes en el Centro de Estudios Políticos y Constitucionales'.

\footnotetext{
"Autobiografia" en Revista Anthropos No 59, 1986. En tales últimos quehaceres lo reemplazo felizmente para sus alumnos un gran jurista hispano como es Javier liménez Campo.
} 
La prolífica y erudita obra de García Pelayo está recogida en sus "Obras Completas", editadas por el Centro de Estudios Políticos y Constitucionales, paradójicamente institución conocida en el pasado como Instituto de Estudios Políticos, que bajo el franquismo había servido de "riñón" de los "intelectuales y juristas" del régimen fascista. La obra fue lanzada con la presencia del entonces presidente de Gobierno, Felipe González M.

En este lugar acometemos una suerte de recensión o comentario un poco tardío, pero actual a los temas de hoy sobre la democracia constitucional y sus límites, de su última obra "El Estado de Partidos", publicada bajo el sello de Alianza Editorial S.A., Madrid, en $1986^{3}$.

El profesor García Pelayo recomendaba a sus alumnos y discípulos leer y (re)leer a los clásicos, probablemente en dos etapas de la vida: en los primeros pasos de formación y en la de madurez. En esta ocasión invitamos a leer y en nuestro caso a (re)leer esta obra del maestro español, que en los términos de Bobbio es un "clásico", ya que soporta el paso del tiempo, y es esencial en la formación del jurista en el Derecho Público que habla y escribe en nuestra lengua ${ }^{4}$.

Además leer o (re)leer a García Pelayo es un pretexto para agregar algunas líneas críticas acerca del Estado de partidos y de los recurrentes críticos de la democracia de partidos y de la "partidocracia", que ocultan, con fines ideológicos inconfesables, en definitiva la centralidad institucional de los partidos en las democracias constitucionales de hoy.

\section{El Estado de partidos}

Comentar la última obra García Pelayo resulta una tarea difícil para quien reconoce en él y su contribución teórico-práctica, a un maestro del Derecho Público y las ciencias sociales, roles que coronó con la presidencia del Tribunal Constitucional espańol. Intentaré cumplir con cierto decoro el cometido de comentarista.

Nuestro autor divide su libro en seis capítulos para captar una de las "dimensiones de la configuración del Estado democrático de nuestro tiempo y concretamente de la presencia y efectos de los partidos políticos en la estructura estatal" (p. 10). El capítulo I contiene una introducción histórica al tema: "Estado de Partidos". Los partidos políticos surgen en Inglaterra con la "germinación del régimen parlamentario", pero es en Alemania donde surge la preocupación teórica en torno a la articulación de los partidos en la estructura del Estado; puesto que la teoría del Estado por sus exigencias gnoseológicas debía abordar este tema, a la luz de la premisa teórica-metateórica de la separación Estado - sociedad civil propia de la modernidad (G. Hegel), y de la "fuerte tensión" entre

"Obras Completas", Edita Centro de Estudios Constitucionales, 3 votumenes, Madrid, 1991.

Consultar en "Obras Completas", Edita CEC, Madrid, 3 vol. II, pp. 1969-2078.

Bobbio, Norberto: “Teoría General de la Política”, Edición a cargo de M. Bovero (Trad. A. de Cabo y G. Pisarello),

Edit. Trotta, Madrid, 2003. También recopilación de José Fernández Santillán: “Norberto Bobbio - El Filósofo y la Política. Antologia” Edit. FCE, $1^{2}$ ed. 1996, 2a ed. 2002, la reimpresión México DF, 2004. 
el componente monárquico-burocrático y el componente parlamentario del Estado. El Estado, realidad de la idea ética, totalidad y expresión de los intereses generales, encuentra su "verdad" en lo político; derivándose toda una teoría del Estado en torno al Estado-Autoridad (Obrigkeitsstaat) que dejó profundas huellas en la teorización sobre la monarquía constitucional base del constitucionalismo clásico (en que lo permanente de la estructura dualista del poder, es el monarca con su Gobierno, Burocracia y Ejército, y lo transitorio, el Parlamento). En Alemania para la teoría constitucional (y en el proceso político real) "el Gobierno, en tanto que representante de los intereses del Estado se contrapone a los partidos como representantes de los intereses particularizados de las ramas profesionales, económica, territoriales y de comunidades religiosas" (p. 24). Así, Georg Jellinek, corifeo de la Escuela del Derecho Público alemán, en su "Teoría General del Estado" concluye que "los partidos son formaciones sociales, y en este sentido ya no son objeto de la doctrina del Estado" (T.G.E. p. 83).

En el capítulo II se estudia el surgimiento del concepto "Estado de partidos" en la teoría Constitucional y en la teoría del Estado, durante el período de la república de Weimar. Son dos grandes tendencias las que surgen en torno al "Estado de partidos, son teóricas, filosóficas y políticas. Una tendencia "mantiene una actitud positiva hacia tal tipo de Estado y que postula el reconocimiento de los partidos políticos por las normas jurídicoconstitucionales" (p. 30) (R. Thoma, H. Kelsen y G. Radbruch). La otra tendencia "está constituida por las que reconocen la realidad del Estado de partidos, pero mantienen una actitud crítica hacia él, o niegan la posibilidad de su reconocimiento jurídico" (p. 37) (O. Koellreuter, C. Schmitt y H. Triepel). En estas tendencias opuestas se resume la contradicción central de Alemania y de Europa de entreguerras: democracia o autocracia, o más precisamente democracia y fascismo como bien observó $\mathrm{H}$. Heller, en unos de sus trabajos anteriores al hundimiento de la República de Weimar5.

En el capítulo III se aborda la constitucionalización de los partidos políticos como realidad en el mundo de la postguerra. García Pelayo sobre este punto escribe: "En todas estas Constituciones se trata de otorgar reconocimiento jurídico constitucional a algo ya preexistente en la praxis política, tan preexistentes que las propias Constituciones deben su existencia a los partidos con representación en la Cámaras constituyentes o con funciones constituyentes" (p. 49). La constitucionalización de los partidos no se agota en su regulación en el texto constitucional, sino que puede complementarse o desarrollarse con normas legales configuradoras de verdaderos estatutos. Con agudeza advierte nuestro autor: "Sin embargo, los partidos políticos tienden a resistir una regulación legal específica ya que ella, junto a ciertas ventajas, conlleva una limitación de su libertad de organización y acción, una publicidad de sus recursos y un cierto control por parte del Estado" (p. 51, 52). De esta manera se puede distinguir en grados de constitucionalización: a) simple reconocimiento constitucional sin legislación específica de partidos (Italia y Francia); b reconocimiento constitucional y una laxa ley de partidos

Heller, Hermann: "Escritos Políticos" (Prólogo y selección A. López Pina, trad. S. Gómez de Arteche), Alianza Editorial, Madrid, 1985, pp. 283-301. 
(España), y c) amplio reconocimiento constitucional y una ley estatutaria de partidos (República Federal de Alemania y Portugal). El status de los partidos políticos de libertad externa (derechos y deberes del partido), libertad interna (derechos y deberes en el partido) y el derecho a prestaciones del Estado, son materias de regulación por los ordenamientos jurídicos que determinarán la amplitud de la normación de estos y su posición constitucional en la estructura del Estado. Finalmente, al comentar la jurisprudencia sobre la posición constitucional de los partidos en la estructura del Estado, de los Tribunales Constitucionales de Alemania y España, García Pelayo escribe: "El Tribunal ha establecido que los partidos sólo pueden insertarse en la Constitución y ejercer las funciones de órganos constitucionales si se sustentan sobre los valores fundamentales del orden constitucional democrático y libre, pues de otro modo quizá puedan existir como grupos sociales, pero es inconcebible que puedan cooperar recta y responsablemente en la formación de la voluntad del Estado jurídicamente garantizada, es decir que puedan cumplir con su función o como partido" (...). "En resumen, parece que puede afirmarse que en las doctrinas jurisprudenciales expuestas, los partidos se muestran como pertenecientes a una esfera a caballo de la sociedad y del Estado, de lo público y lo privado, participando de ambos sin pertenecer exclusivamente a ninguno de ellos, lo que, por otra parte es una proyección mental de la difuminación de los límites precisos entre la sociedad y el Estado o entre lo público y lo privado y donde, por consiguiente, más que de fronteras lineales claras y distintas cabe hablar de Marcas o territorios intermedios" (p. 69-70). Esta dialéctica socialización-estatalización, es una de las notas definidoras del Estado del capitalismo tardío, como observa García Pelayo en su libro: "Las Transformaciones del Estado Contemporáneo".

En los capítulos $\mathrm{N}$ y V se analizan la democracia de partidos y el "Estado de partidos". La democracia de partidos es "una adaptación del principio democrático -cuya enunciación cuenta con más de veinticinco siglos de existencia-a las nuevas coyunturas históricas y muy concretamente a dos factores conexionados entres sí. El uno es la masificación del ejercicio de los derechos democráticos debido no sólo al crecimiento demográfico de la sociedad, sino también a la extensión del sufragio... El otro consiste en el hecho de que la sociedad organizacional..." (...) "Cuando ello se proyecta al campo político, los partidos se nos muestran como organizaciones sin cuya medición no es posible actualizar los principios democráticos en las condiciones de la sociedad de nuestro tiempo. En efecto, el pueblo amorfo sólo puede manifestar su voluntad si se somete a un proceso organizativo llevado formalmente a cabo por la legislación electoral y material por la acción de los partidos, en razón de que sólo éstos pueden cumplir aquellas funciones, sin las cuales no hay posibilidad de realizar la democracia en las condiciones que presente" (p. 73-74-75). En la "sociedad organizacional" contemporánea, los partidos cumplen las funciones siguientes: movilizar las masas para su participación e integración en el proceso democrático; transformar orientaciones y actitudes políticas generales en "programaciones de acción política nacional y convertir necesidades en pretensiones precisas y concretas a satisfacer por los poderes públicos (con la consiguiente flexibilidad ideológica de los partidos); las demandas son integradas y sistematizadas por los staffs en programas 
coherentes de acción capaces de entrar a competir por el electorado y de inspirar las líneas de decisiones y acciones del Estado del Gobierno o desde la oposición; informar a los electores logrando una mínima racionalidad en el derecho de sufragio; la oferta de elites políticas capaces de renovar las dirigencias actuales y finalmente, los partidos ofrecen al electorado su potencial organizativo. Para explicar la realidad del Estado de partidos, nuestro autor recurre al supuesto de que el Estado democrático es un Estado neutral en el sentido de no estar vinculado a un partido determinado, sino a preceptos y valores constitucionales (es decir, un Estado abierto a todos los partidos). De esta manera el Estado de partidos es definido como un "Estado en el que las decisiones y acciones de un partido o de unos partidos llevadas a cabo dentro del marco de la organología estatal se imputan jurídicamente al Estado, aunque políticamente sean imputables a la 'mayoría parlamentaria' o al 'partido en el poder" (...) "El Estado de partidos es un producto de la interacción entre dos sistemas: de un lado, del sistema jurídico-político entendido aquí como un conjunto de órganos cuya estructura, competencias y relaciones recíprocas han sido configuradas jurídicamente; de otro, del sistema sociopolítico de los partidos compuestos por unas organizaciones de formación libre en relaciones de concurrencia entre sí por el ejercicio o la participación en el ejercicio del poder del Estado, dotadas de sus propios objetivos, de su propia disciplina y por tanto, de sus propias relaciones de supra y subordinación, y obedeciendo a su propia dialéctica" (p. 87, 89-90). Los partidos políticos se insertan en los órganos políticos del Estado, pero en el Estado democrático esta inserción está sujeta a las reglas del juego (una de ellas la alternancia en el poder, como consecuencia de elecciones libres y competitivas).

Para concluir, el capítulo VI de este libro se refiere a los límites del Estado de Partidos. El Estado de Partidos es una dimensión o componente del Estado democrático y encuentra sus límites en otros componentes y condicionamientos del sistema estatal (jurídicos y funcionales-institucionales). El Estado de Partidos es una dimensión del Estado democrático de Derecho, "un Estado en el cual tanto el proceso democrático como los actores de este proceso están sometidos a la Constitución y a la Ley, un Estado en el que la voluntad de la mayoría no es por sí sola legítima, ni justa, ni sabia; un Estado, en fin, en el que el Derecho es el marco y medida de legitimidad de su acción" (p. 119).

El Derecho es un medio de la política, un producto de la política pero también, "una racionalidad objetivada, un ordenamiento o sistema normativo que sirve de marco y medida de legitimidad para la acción de los actores políticos" (...) "El Derecho se nos muestra, así como una racionalidad impersonal y objetiva que en cada momento trasciende como totalidad a los actores en juego y al que estos han de adaptarse para que su acción sea legítima" (p. 118-119). Además, el Estado de Partidos tiene límites funcionales-institucionales, "Las derivadas de los requisitos necesarios para el cumplimiento de una función estatal unida a un espíritu corporativo o profesional-estamental que enraíza en las profundidades históricas del Estado occidental, bien que debilitado en el tiempo presente" (p. 120,121). Estos límites concretos funcionales-institucionales son: la Administración pública (autónoma e imparcial entre los partidos, pero subordinada lealmente a la realización del programa político del Gobierno, con un estatuto 
específico, conciencia estamental y sujeta al principio de legalidad) y la jurisdicción (con una actividad judicial neutral frente a los partidos, sujeta al principio de legalidad y al sistema de la organología estatal).

Este capítulo final contiene, a mi juicio, una defensa bastante acrítica del Estado de Partidos, del Estado Social de Derecho; que es la defensa de la racionalidad del poder organizado bajo la forma estatal, de una determinada forma histórica de dominación política. El apego a los dogmas, principio y categorías abstractas de la teoría del Estado y Constitucional clásica y contemporánea (reflejo de una consideración metateórica positiva del Estado y del poder como realidad de la idea ética: la libertad) impide la labor teórico-crítica, pilar fundamental de la reconstrucción de la teoría jurídico estatal basada en el principio democrático. Con todo, lo anterior no significa desconocer el carácter progresivo del Estado moderno y la democracia representativa-formal. La democracia formal, la democracia política es el único instrumento para la construcción de una democracia social-participativa. El estudio del Estado de Partidos debe eludir caer en los tópicos formalistas o en los tópicos autoritarios, justificatorios o críticos de la democracia política. El libro del profesor García Pelayo, a pesar de su actitud relativamente acrítica en relación al Estado de Partidos no cae en tópicos, penetra con agudeza en todas las múltiples facetas de esta realidad del Estado contemporáneo a partir del principio democrático. García Pelayo demuestra un hecho palmario: la democracia política es una democracia de partidos, el Estado democrático es un Estado de partidos.

La crítica sugerente y falseada de un Schmitt a la democracia parlamentaria como una democracia de partidos es una demostración palmaria de que detrás de la crítica al Estado de Partidos y a la "partidocracia" usualmente se ocultan teorías y metateorías autocráticas, que trabajan en la praxis por la destrucción de la democracia política.

Finalmente, el libro del maestro García Pelayo termina con dos anexos: "El Estado de partido único" y "Leyes de Partidos". En el primer anexo, la monografía "El Estado de partido único" analiza desde un enfoque a la ciencia política el partido bolchevique de la Unión Soviética, el fascismo italiano y el nacionalsocialismo. El segundo anexo "Leyes de Partidos" produce los textos actualizados de las leyes de partidos políticos de la República Federal Alemana, de la República de Austria y de la República de Portugal.

\section{Democracia constitucional y partidos}

En cuanto al origen de los partidos políticos la tesis que goza de mayor predicamento, es aquella que fija su origen remoto en la ruptura revolucionaria inglesa del siglo XVII, evolucionando lentamente en el siglo XVIII para terminar conformándose en el siglo XIX, con las reformas electorales que se inician en 1823 (K. Lenk - F. Neumann, R. García Cotarelo, entre otros) $)^{6}$. En su clásico libro "Los Partidos Políticos", el longevo

Lenk, Kurt y Neumann, Franz (eds.), "Teoría y Sociologia de los Parcidos Políticos" (trad. Ignacio de Otto) Edit. Anagrama, Barcelona, 1980. También de Ramón García Cotarelo: "Los Partidos Políticos" cdit. Sistema, Madrid, 
jurista y politólogo francés Maurice Duverger une el origen histórico de los partidos a las elecciones y la representación: "En 1850, ningún país del mundo (con excepción de los Estados Unidos) conocía partidos políticos en el sentido moderno de la palabra: había tendencias de opiniones, clubes populares, asociaciones de pensamiento, grupos parlamentarios, pero no partidos propiamente dichos (...). "En general, el desarrollo de los partidos parece ligado al de la democracia, es decir, a la extensión del sufragio popular y de las prerrogativas parlamentarias" (Duverger) ${ }^{7}$. La conclusión lógica es ligar en el origen (origen interno) de los partidos los grupos parlamentarios y los comités electorales. También los partidos políticos encuentran su origen (origen externo) en asociaciones y grupos (sindicatos, mutualidades, sociedades de intelectuales, iglesias, asociaciones de antiguos combatientes, sociedades secretas y grupos clandestinos). Estos partidos, como regla general, son más centralizados, coherentes y disciplinados. De esta manera, la creación electoral y parlamentaria parece corresponder a un tipo antiguo y la creación exterior a un tipo moderno de partido, coherente con la evolución histórica de la democracia liberal (Duverger).

Los partidos políticos y las organizaciones humanas han desarrollado tendencias oligárquicas reforzadas por la naturaleza misma de la política (política-alienación), contribuyendo a reforzar los rasgos autoritarios de la democracia política contemporánea, como tempranamente observó el sociólogo Robert Michels en 1911 y más tarde en su clásico "Partidos Políticos".

La "ley de hierro de las oligarquías en los partidos políticos" (Michels) es una realidad en los partidos de notables y en los partidos de masas; más aún la crítica de Michels (que primitivamente comulgó con la socialdemocracia alemana para terminar en los brazos del fascismo europeo) se planteó al SPD germano anterior a la Gran Guerra, un partido que acompaña a sus miembros de "la cuna a la tumba" y que fue modelo para la socialdemocracia internacional ${ }^{8}$.

La doctrina del Derecho Público alemán consideró a los partidos como "formaciones sociales", negando su inclusión en la teoría del Estado y en el ordenamiento jurídico. (G. Jellinek). Sólo bajo la República de Weimar, un sector minoritario de la ciencia jurídica admite la inclusión de los partidos políticos dentro del ámbito cognoscitivo científico (H. Heller) y realizan una férrea defensa de la democracia política como democracia de partidos (H. Heller, G. Radbruch, H. Kelsen, R. Thoma), frente a los numerosos juristas enemigos de la democracia alemana y europea. El "microcosmos cultural" de Weimar y centroeuropeo va a decantar los grandes temas de la teoría del Estado y la teoría de la Constitución de época y del siglo XX, que tienen como centro

1985.

Duverger, Maurice: "Los Partidos Políticos" (trad. J. Campos y E. González Pedrero), FCE, 1ª ed. Especial 1957, 4a reimpresión, 1972, México DF, 1972.

* Michels, Robert: "Los Partidos Políticos. Un estudio sociológico de las tendencias oligárquicas de la democracia moderna”. (trad. E. Molina de Vedia, 1969, 4a reimpresión 1991, Edit. Amorrortu, Buenos Aires, 2 vol., 1991. 
a los partidos: Estado de partidos, democracia política, democracia social, sistema electoral y régimen político.

En relación a los partidos políticos, existen dos cuestiones centrales en la teoría y praxis de la democracia constitucional contemporánea:

- Constitucionalización de los partidos políticos

- Definición de los partidos como instrumentos para la "activación democrática del pueblo".

A partir de la teoría praxis del constitucionalismo democrático y social, la constitucionalización de los partidos y su rol de "activación democrática del pueblo", deben asegurarse mediante: un status constitucional específico, un funcionamiento efectivo de las organizaciones bajo un principio de democracia interna, una efectiva defensa y promoción de los derechos humanos como elementos fundacionales del Estado de Derecho, y el respeto de las reglas del juego y de estrategia de la democracia política (Bobbio) ${ }^{9}$.

De este modo el partido político podrá cumplir sus roles centrales en la democracia constitucional. En efecto, el partido político se plantea como una organización dotada de un programa y que realiza un conjunto de funciones sociales e institucionales conducentes a la "conquista del poder". Las funciones predominantemente sociales del partido, son entre otras: a) socialización política, b) la organización y movilización de la opinión pública, c) la representación y articulación de plurales intereses, d) la legitimación de la totalidad del sistema político. Las funciones del partido predominantemente institucionales: a) reclutamiento y selección de élites, b) organización y realización de elecciones, c) organización y funcionamiento del Parlamento, d) composición y funcionamiento del Gobierno.

Esta doble agrupación de funciones descubre la doble "naturaleza" del partido político como institución política (Duverger, Sartori), es decir, configuradora de una "naturaleza mixta" entre la asociación y el órgano del Estado ${ }^{10} \mathrm{La}$ juridificación-constitucionalización de los partidos políticos, no los convierte en órganos del Estado, pues ello los transformaría en instrumentos monopolizadores de la formación de la voluntad del Estado, cerrando el camino a la acción transformadora de los movimientos sociales.

Para concluir sólo resta anotar que los partidos políticos en la democracia constitucional, se erigen en piezas inevitables y centrales de funcionamiento de la democracia política y del sistema político, y al mismo tiempo transforman la democracia liberal en democracia de partidos, en que frente a las instituciones formales del proceso político, se erige un "locus" real de decisión que son los partidos y sus oligarquías o élites, que importan un peligro para la participación de la ciudadanía en un proceso político democrático abierto

Entre muchos trabajos de Norberto Bobbio consultar "El Futuro de la Democracia" (trad. J. Moreno) Plaza-Janes Editores S.A., Barcelona, 1985.

16. Sartori, Giovanni: "Partidos y Sistemas de Partidos. Marco para un Análisis", Abaria Editorial, Madrid, 1980, vol 1. También Manuel Martinez Sospedra: "Introducción a los partidos políticos", Edir. Ariel, Barcelona, 1996. 
y plural, por lo que la constitucionalización de los partidos y "activación democrática del pueblo" exigen los resguardos necesarios que impidan a éstos el monopolio de la participación y decisión, conservando el pueblo o ciudadanía un espacio en los partidos y fuera de éstos, alejando la imposición de modelos elitistas de democracia, y que permitan conservar la democracia constitucional como definición básica del edificio estatal.

El constitucionalismo democrático y social nos lleva a sostener una "democracia exigente" (Bobbio), crítica de sus paradojas o contradicciones, y a defender una racionalidad crítica del orden político, lejana del "fetichismo constitucional", pero metodológicamente normativista ${ }^{11}$.

García Pelayo puede ser referido en parte a estas coordenadas, lo que se ilustra en una célebre entrevista publicada en la Revista Anthropos en 1986, en que dice: "Una cosa es la génesis de algo y otra distinta lo que sea ese algo. Es cierto que la Constitución, como todo lo creado por el hombre, surge en una coyuntura histórica dada y, en este caso, con sus propias constelaciones de fuerzas políticas y sociales. Pero la significación esencial y existencial de una Constitución no radica en su dependencia de las situaciones en que tuvo lugar su nacimiento que, como he dicho, son con modalidades distintas, comunes a todas las creaciones humanas, sino en su carácter de norma suprema del orden político y jurídico de un pueblo. Dicho de otro modo, no es desde la facticidad, sino desde la normatividad, desde donde cabe explicar la Constitución.". La Constitución es en último término expresión de una "racionalidad objetivada", lo que no importa renunciar a una racionalidad crítica para construir la democracia constitucional como "democracia exigente" en que sus reglas se funden y aseguren la libertad negativa-libertad positiva e igualdad. 